\title{
A synthetic hydroxypropenone inhibits nitric oxide, prostaglandin E2, and proinflammatory cytokine synthesis
}

\begin{abstract}
HMP [3-(2-hydroxyphenyl)-1-(5-methyl-furan-2-y-1) propenone] was evaluated for its ability to inhibit the synthesis of major proinflammatory mediators and cytokines in interferongamma (IFN-gamma)- and lipopolysaccharide (LPS)-induced RAW 264.7 cells and phorbol myristate acetate (PMA)-differentiated/LPS-induced U937 cells. HMP suppressed the production of nitric oxide (NO) with significant inhibitory effects at doses as low as 0.78 microM $(\mathrm{P}<0.05)$. Prostaglandin E2 (PGE2) secretion was also inhibited at doses of 12.5 microM and above $(\mathrm{P}<0.01)$. The secretion of both TNF-alpha and IL-6 were only inhibited at the highest dose used $(25 \mathrm{microM}$; P < 0.001). IL-1beta secretion was also inhibited from 12.5 microM onwards $(\mathrm{P}<0.01)$. This inhibition was demonstrated to be caused by downregulation of inducible enzymes, inducible nitric oxide synthase (iNOS), and cyclooxygenase-2 (COX-2), without direct effect upon iNOS or COX-2 enzyme activity. HMP only inhibited iNOS $(\mathrm{P}<0.001)$ and IL-1beta $(\mathrm{P}<0.05)$ gene expression at the highest tested concentration. HMP did not affect the secretion of chemokines IL-8 and monocyte chemotactic protein-1 (MCP-1) and the anti-inflammatory cytokine IL-10. The most striking effect of HMP was its NO inhibitory activity and therefore we conclude that HMP is a selective inhibitor of iNOS.
\end{abstract}

Keyword: COX-2; Cytokines; Hydroxypropenone; INOS; RAW 264.7; U937 